\title{
UN NOU FORT ROMAN LA CUMIDAVA-RÂŞNOV*
}

\section{OVIDIU ȚENTEA, AleXANDRU PoPA, LiVIU PETCULESCU}

\section{A NEW ROMAN FORTLET AT CUMIDAVA-RÂȘNOV}

This study presents the most relevant results of the geophysical surveys carried out in the framework of the LIMES National Program within the Râşnov - Cumidava fort and civil settlement.

The Râşnov Roman Fort was considered in its first phase, namely between 101-118 AD, as a component part of the northern frontier of the province of Moesia Inferior, which would have been extended at that time also in the south-east of Transylvania. The strategic role of the fort would have been to defend the access point in the province from the north through The Bran Pass. After 118/119 AD it would have become a fortification of Dacia Inferior.

The most important result of the magnetometric research is the discovery of a fortlet (with the dimensions of 73 by $50 \mathrm{~m}$ ). It had two entrances on the West and East sides. Inside, you can see the prints of some building complexes, arranged along a road that connects the two entrances.

The archaeological verification of the result of the geophysical survey was done by excavating in 2017 a section where the third (outer) ditch of the larger fort and the ditch of the small fortification was discovered. The best known analogy for the small fortification at Râş̧nov is the Castleshaw fortlet.

This new fortlet is the earliest Roman fortification known in Râșnov, and can be connected with the functioning of the small fortification in Rucăr (dated between 102-118 AD). Through this discovery, we obtained a new archaeological argument on the link between the legionary camp at Novae and the southeast of Transylvania on the Transalutanus line dating from the reign of Emperor Trajan.

KEYWORDS: Dacia, frontiers, limes, fortlet, geophysical survey.

CUVINTE CHEIE: Dacia, frontiere, limes, fort, prospecțiuni geofizice.

\section{INTRODUCERE}

$\mathrm{Cu}$ toate că arhitectura militară romană pare la o primă vedere foarte standardizată, pe măsură ce castrele sunt cercetate mai detaliat se disting structurile particularizate, care se deosebesc de schema general acceptată. Un exemplu elocvent în acest sens ne oferă castrul din preajma oraşului Râşnov, identificat cu numele antic de Cvmidava. Din punct de vedere strategic, importanța acestui castru ține de amplasarea sa specială în teritoriu, acesta fiind corespondența în sud-estul Transilvaniei, a fortificației de la Rucăr ${ }^{1}$, ambele având rolul de a supraveghea accesul prin pasul Bran-Rucăr.

Fortificația este situată pe un grind, dispus între cursurile râurilor Bârsa (sud-vest) şi Ghimbăş̧el (nord-est), la aproximativ $500 \mathrm{~m}$ de cursul actual al Bârsei. Situl se află la aproximativ 3 km nord-vest de localitatea modernă Râşnov, la nord-est de drumul modern care asigură comunicarea între Cristian şi Vulcan. Locul pe care a fost ridicat castrul, este cunoscut de populația locală drept „Grădişte” sau „Erdenburg”. Astăzi, în teren se distinge traseul patrulater al fortificaţiei, precum şi intervențiile săpăturilor arheologice efectuate de-a lungul timpului. Amprentele vechilor săpături nu se mai observă decât pe alocuri și cu o oarecare dificultate. În exteriorul incintei, cu precădere către nord și vest, sunt vizibile la suprafaţa solului urme ale unor presupuse ruine și fragmente ceramice, aparţinând probabil aşezării civile din preajma castrului.

Primele informații despre existența castrului roman de la Râş̧nov au apărut în a doua jumătate a secolului XIX-lea. Primele cercetări sistematice din castru au fost conduse de Mihail Macrea abia în anul $1939^{2}$. Cu ocazia acestor intervenţii, au fost dezvelite cele patru porţi, precum şi turnurile de colţ. În paralel s-au mai efectuat două secţiuni diagonale, devenite tradiţionale pentru cercetările acelei epoci. Prin intermediul acelor secţiuni lungi, dar foarte înguste, au fost semnalate mai multe clădiri din

\footnotetext{
* Acest studiu a fost realizat în cadrul Programului Național LIMES, finanțat de Ministerul Culturii și Identității Naționale.

${ }^{1}$ Bogdan Cătăniciu 1974, 277-288.

${ }^{2}$ M. Macrea a publicat o inscripție descoperită în castru, ocazie cu care a furnizat şi unele informații referitoare la structura castrului: Macrea 1944, 234-261. Alte detalii la Macrea 1969, 227, 228, 232.
} 
interiorul fortificaţiei. Ulterior, în perioada anilor 1969-1974, săpăturile au fost continuate, fiind cercetate elemente ale incintei pe toate cele patru laturi, precum şi cele patru porţi şi turnurile de colţ. Au mai fost dezvelite părţi din clădirile A-E la fel ca şi clădirea comandamentului. Cercetările din anii 1969-1970 au fost publicate în formă monografic $\breve{a}^{3}$, restul fiind prezentate prin rapoarte de săpătură ${ }^{4}$.

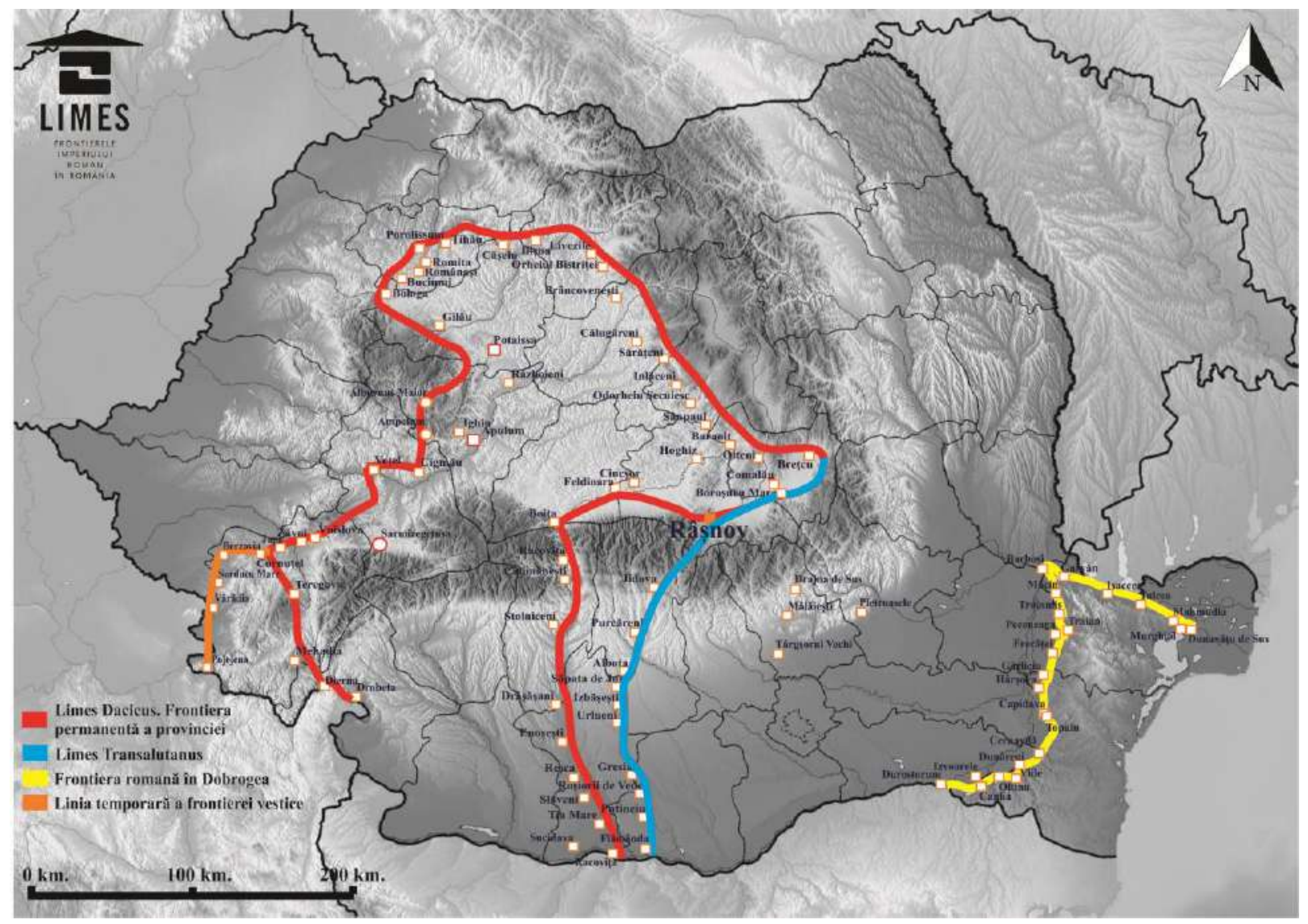

FIGURA 1: Harta frontierelor romane din România, cuprinzând localizarea castrului de la Rășnov (Programul Național LIMES - https://limesromania.ro/ro/articole/despre-proiect).

Potrivit autorilor cercetărilor, acest castru ar fi avut două faze principale de existenţă. În prima fază, castrul era apărat de un val de pământ $(114 \times 110$ m), dublat de un şanţ de apărare. În cea de-a doua fază a fost construită o incintă din zid de piatră $(124 \times 118 \mathrm{~m})$, plan dreptunghiular; orientat cu colţurile spre punctele cardinale principale. Porta praetoria se afla pe latura de nord-est, fiind orientată spre pasul Bran 5 .

Pe baza datării unor artefacte și pe unele observații asupra arhitecturii porţilor, castrul a fost datat în perioada târzie a domniei lui Hadrian sau la începutul domniei lui Antoninus Pius. Trupa atestată aici este VI nova Cumidavensium Alexandriana Severiana? / Vindelicorum p. f. Cumidavensis Alexandrianae. Porţile și alte clădiri din interior au fost reconstruite sau reparate după domnia lui Severus Alexander6.

\footnotetext{
${ }^{3}$ Gudea, Pop 1971.

${ }^{4}$ Gudea, Pop 1973, 13-24; Gudea, Pop 1974-1975, 55-78; Gudea, Pop 1975, 56-72; Petculescu et alii 2014, 175; Petculescu et alii 2015, 113-114; Petculescu et alii 2016, 62-63; Petculescu et alii 2017, 68-69; Petculescu et alii 2017, 111-112; Petculescu et alii 2018.

5 Pentru prezentarea și interpretarea detaliată a clădirilor din interiorul castrului, vezi Marcu 2009, 222-229. Vezi de asemenea și Vlădescu 1983, 124-125; Gudea 1997, 65-66, nr. 42.

${ }^{6}$ IDR III/4, 221; Piso 1993, 192-196, nr. 5.
} 
Castrul de la Râşnov a fost considerat, în prima sa fază, adică între anii 101-118, drept parte componentă a frontierei nordice a provinciei Moesia Inferior, care ar fi fost extinsă în acea perioadă şi în sud-estul Transilvaniei. Rolul strategic al castrului l-ar fi constituit apărarea intrării în provincie dinspre nord, prin pasul Bran. După anii 118/119 ar fi devenit o fortificaţie a provinciei Dacia Inferior ${ }^{7}$.

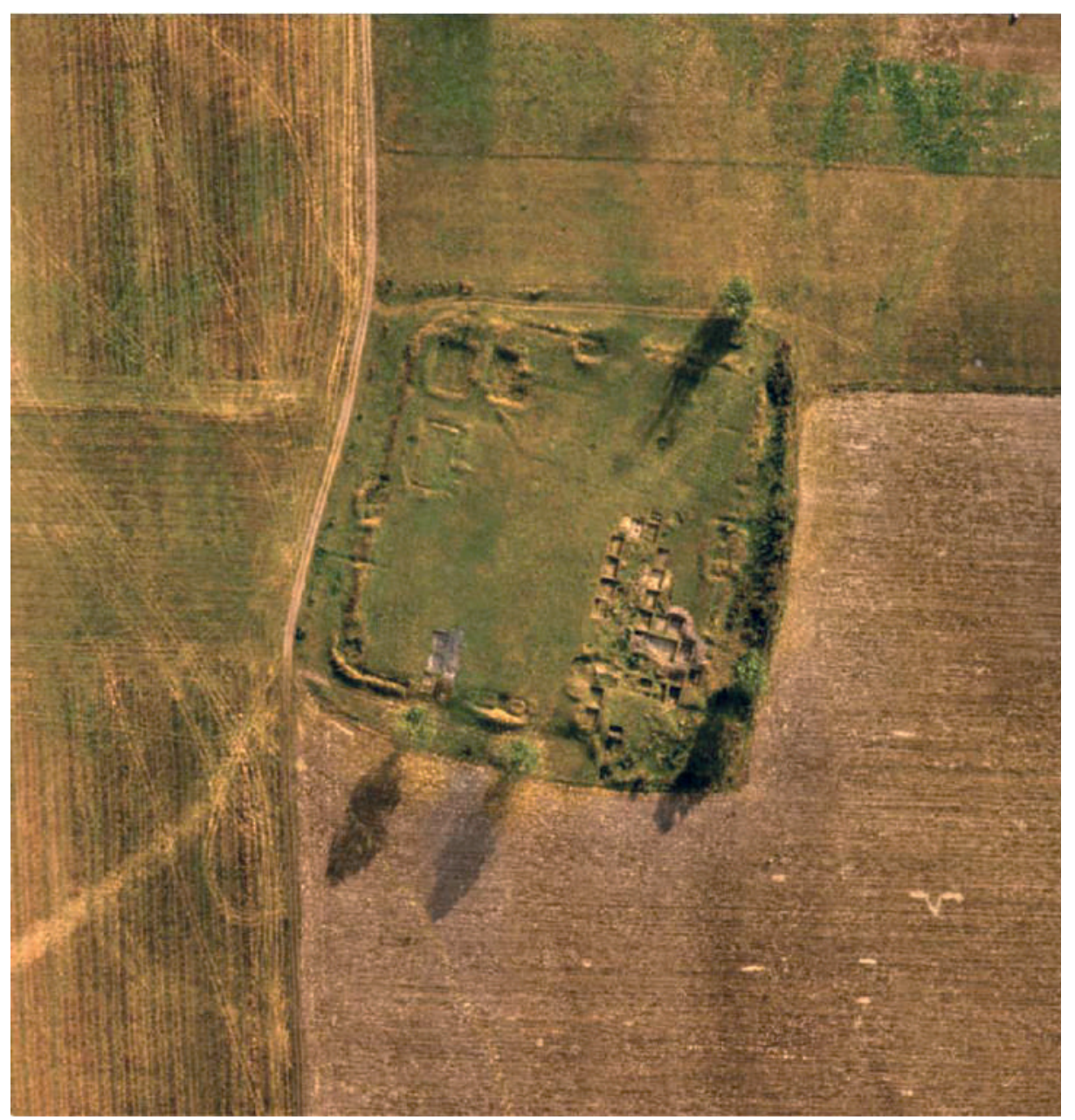

FiguRa 2: Castrul și așezarea de la Râşnov, detaliu din ortofotoplan - Daniel Costea - 2016, OMNIR

\section{CERCETĂRI DE TEREN ÎN CADRUL PROGRAMULUI NAȚIONAL LIMES}

$\mathrm{Cu}$ ocazia desfăşurării Programului Național LIMES, accentul cercetărilor de teren s-a pus pe înregistrarea topografică a datelor vizibile pe teren şi pe măsurători geofizice. Deoarece în trecut, în jurul fortificaţiei au fost identificate mai multe puncte cu descoperiri de ceramică, care ar atesta existenţa unui vicus militar, s-a decis desfăşurarea unor investigaţii extinse mai ales în exteriorul zidurilor fortificaţiei de la Râşnov.

Din punct de vedere tehnic cea mai adecvată metodă de cercetare a fost considerată magnetometria, care se bazează pe interpretarea contrastului valorilor câmpului magnetic al suprafeței solului într-un punct anumit şi al câmpului magnetic natural al pământului. Această diferență permite evidențierea de anomalii magnetice care indică existenţa unor structuri subterane de origine naturală sau umană. Utilizată împreună cu alte metode de cercetare, magnetometria permite o recunoaștere

\footnotetext{
${ }^{7}$ Ţentea, Matei-Popescu 2015, 115-118.
} 
mult mai eficientă a urmelor arheologice subterane. Spre deosebire de multe alte metode de cercetare arheologică, magnetometrie posedă particularităti deosebite: rezultatele ei nu depind considerabil de timpul zilei, anotimp, condiții climaterice, culturi agricole sau starea suprafeței solului. În afara de aceasta, metoda oferă posibilitatea de a desluşi structuri arheologice aflate complet sub pământ, până la o adâncime de cca $2 \mathrm{~m}$.

Pentru studierea geomagnetică a suprafeţelor de la Râşnov s-au folosit sonde de tip Fluxgate. Cartarea magnetometrică s-a efectuat în perimetre rectangulare. Vizualizarea datelor achiziționate a fost realizată prin interpolare, folosindu-se algoritmul interpolării bi-liniare şi o scalare lineară a nuanțelor de gri a valorilor interpolate: culoarea neagră corespunde valorilor înalte pozitive, iar culoarea albă corespunde valorilor negative. Iniţial harta magnetică a fost realizată pe baza unui sistem de coordonate locale. În urma georeferenţierii hărților magnetice procesate pe baza fiecărui perimetru măsurat, a fost posibilă îmbinarea acestora într-o singură imagine şi apoi combinarea acesteia cu alte categorii de date spaţiale. Astfel, pentru integrarea rezultatelor obţinute prin măsurări magnetometrice din interiorul castrului, planul rezultat în urma măsurătorilor magnetometrice a fost suprapus cu planul săpăturilor contemporane ${ }^{8}$, precum şi cu planului rezultat în urma săpăturilor arheologice din anii 1969-19749.

În total, cu ocazia lucrărilor din cadrul Programului Naţional Limes, s-a cercetat magnetometric o suprafaţa totală de aproximativ 6 ha.

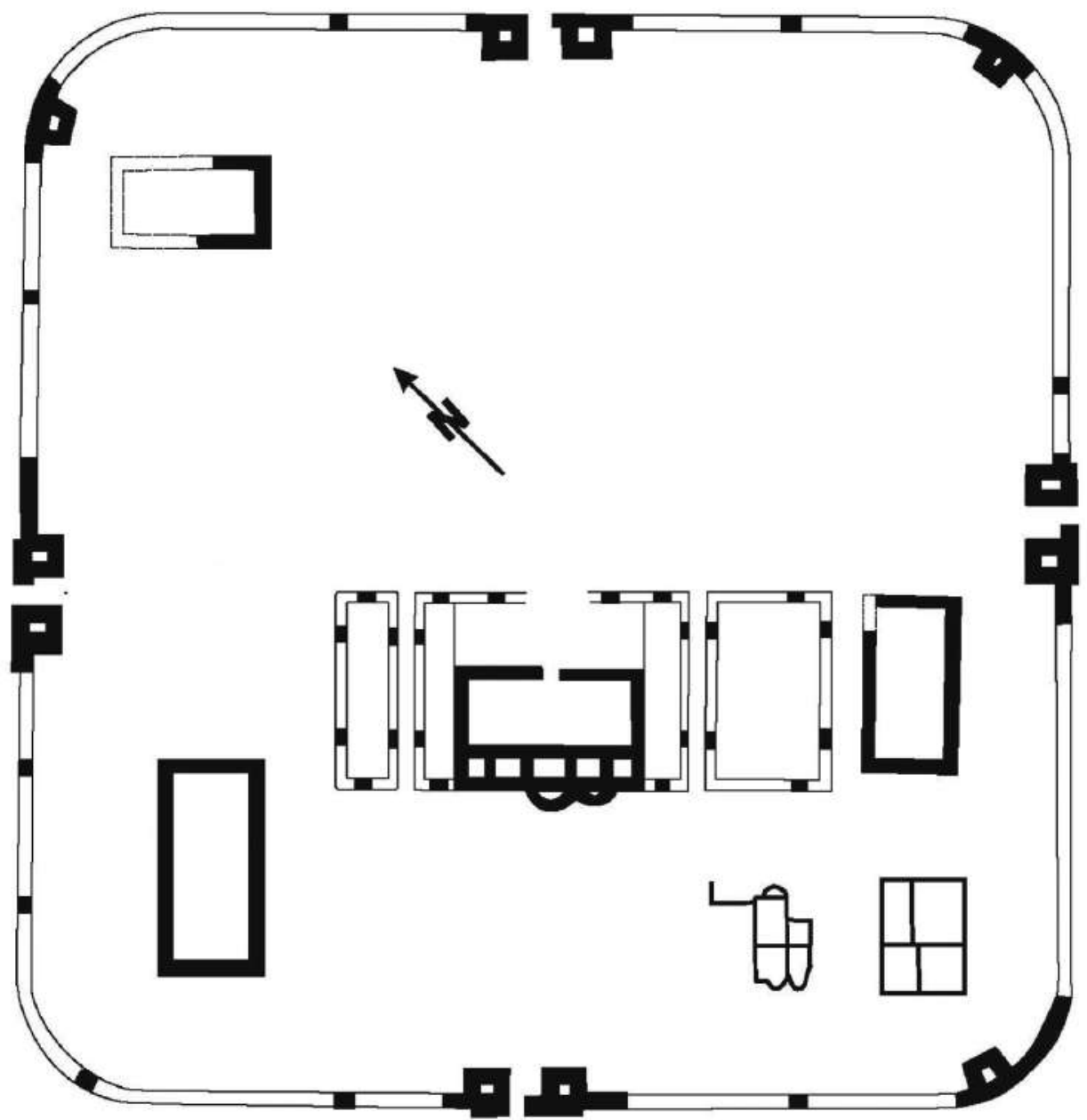

FIGURA 3: Planul castrului de la Râșnov în urma cercetărilor arheologice (după Marcu 2009, 298, pl. 30)

\footnotetext{
${ }^{8}$ Planul a fost preluat din versiunea online a Repertoriului Arheologic Naţional: http://ran.cimec.ro/sel.asp?lang=EN\&imgid=41328.

${ }^{9}$ Gudea, Pop 1974-1975, 55-78.
} 


\section{REZULTATE CERCETĂRILOR NON-INVAZIVE}

În interiorul castrului, harta magnetometrică procesată în condițiile descrise mai sus, conţine o serie de anomalii, dintre care amintim în primul rând cele de formă alungită şi valoare magnetică negativă (culoare deschisă). Coroborând forma şi orientarea acestor anomalii constatăm că ele sunt aproximativ congruente cu secţiunile de săpătură de până la 1974, inclusiv secţiunea dispusă diagonal, care străbătea tot interiorul castrului pe direcţia dintre turnurile/colţurile de nord-est şi sud-vest. Anomaliile cu valoarea magnetică pozitivă ridicată, indică surse de magnetism, care se datorează unor resturi de construcţii. Imposibilitatea de a reconstitui formele acestor construcţii se datorează probabil faptului că castrul a avut mai multe faze de construcții.

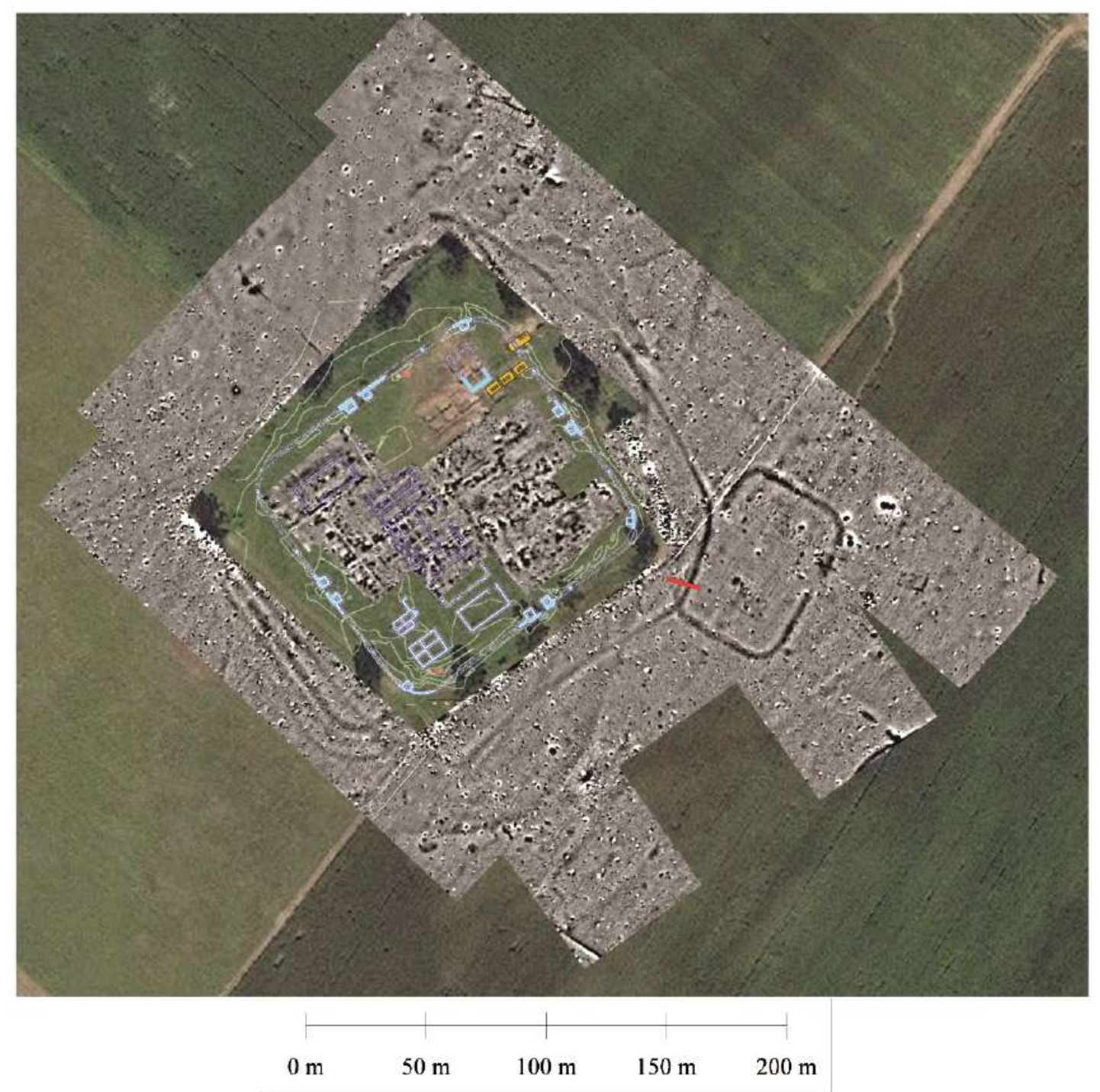

FIGURA 4: Corelarea planului cercetărilor arheologice publicate din castrul de la Râșnov cu rezultatele prospecțiunilor geofizice din anul 2016.

În așezarea civilă au fost identificate câteva elemente semnificative, pe care le vom descrie succinct în cele ce urmează. Se remarcă în primul rând, anomalii de formă alungită şi dimensiuni mari pe lungime, surprinse mai ales la limita zidul de vest al castrului. După părerea noastră acestea reprezintă urmele celor trei șanțuri ale castrului din faza lui „de piatră”. Fiecare dintre acestea au lățimea la suprafaţa actuală a solului de aproximativ 3 metri. Interpretarea celor două traiecte, care 
apar la distanțe variabile de laturile de est sau de nord, nu o vom putea clarifica până la o eventuală extindere a investigațiilor.

În partea de Nord a suprafeței cercetate, la aproximativ 50 metri de colțul nordic al castrului, se remarcă amprentele unor contururi rectangulare, care marchează existența unor clădiri care au funcționat în cadrul așezării civile.

În partea de sud-sud-est al suprafeței cercetate magnetometric, semnalăm o anomalie de formă rectangulară cu dimensiunile de circa $11 \times 6 \mathrm{~m}$ şi o anomalie circulară în partea centrală. Spre nord de aceasta, s-a identificat o altă anomalie, care reprezintă după toate probabilităţile urmele unui cuptor.

Pe de altă parte, cea mai importantă semnalare a cercetării magnetometrice este structura rectangulară cu colţurile rotunjite, care acoperă o suprafaţă de aproximativ $73 \times 50 \mathrm{~m}$. Vizual se disting două intrări, cu deschiderea de circa $6-6,5$ pe laturile de Vest, respectiv pe cea de Est. În interior se pot observa amprentele unor complexe, dispuse de-a lungul unui drum, care unește cele două intrări. Amplasarea porților pe laturile lungi ale fortificației este destul de atipică pentru exemplele cunoscute în lumea romană ${ }^{10}$.

Pentru verificarea arheologică a rezultatului prospecțiunilor geofizice, în anul 2017 a fost trasată o secţiune cu dimensiunile de $15 \times 1$ m (FIG. 4). În cadrul săpăturilor au fost descoperite două şanţuri: cel de-al treilea șanț al castrului mare şi, respectiv, şanţul fortificaţiei mici, identificate prin prospecțiuni geofizice. Agger-ul micii fortificații pare să fi fost nivelat aproape total, pământul din structura sa fiind dislocat peste șanţul corespunzător ${ }^{11}$.

Cea mai bună analogie cunoscută pentru fortificația mică de la Râşnov este fortlet-ul de la Castleshaw $^{12}$. În timpul campaniei lui Agricola din anul 79, acolo apare un castru destinat unei trupe de auxiliari care a fost abandonată în jurul anilor 90. Ulterior, zona pare să fi fost reocupată în jurul anului 105, prin intermediul unui fortlet, care constituie de fapt analogia cu fortificaţia de la Râşnov.

Una dintre ipotezele plauzibile de interpretare a structurii rectangulare de la Râşnov ar fi o fortificație în care putea staționa o garnizoană de circa 60 de oameni, adică o centuria. Distincția terminologică dintre fortlet și small fort a fost făcută prin lipsa clădirilor administrative din interiorul primei $^{13}$.

\section{ÎN LOC DE CONCLUZII}

Cercetările non-invazive efectuate la Râşnov, realizate cu ocazia documentaţiei prin Programul Naţional Limes, indică o locuire intensă nu doar pe interiorul fortificaţiei romane, ci şi în afara ei. Acest fapt indică nevoia imperioasă a extinderii prospecțiunilor din acest areal. Pentru o mai bună organizare a managementului acestui sit arheologic, care urmează să devină parte componentă a sitului UNESCO „Frontiera Imperiului Roman în Europa”, se impune delimitarea clară a sitului.

În stadiu actual al cercetării este foarte greu să avansăm concluzii despre rolul şi rostul fortificaţiei de dimensiuni mici, descoperită prin metode non-invazive şi confirmată prin săpături la Râşnov. $\mathrm{Cu}$ toate acestea, fortlet este cea mai timpurie fortificație romană de la Râş̧nov care, pe baza analogiilor, poate fi datată în primii ani de după cucerirea Daciei. Această fortificaţie timpurie poate fi pusă în conexiune cu funcționarea fortificaţiei de mici dimensiuni de la Rucăr. Prin această descoperire am obţinut un nou argument arheologic privind legătura dintre castrul legionar de la Novae și sud-estul Transilvaniei pe linia transalutană încă din perioada împăratului Traian.

\footnotetext{
10 Fleer 2004, 80-81.

${ }^{11}$ Petculescu et alii 2018.

${ }^{12}$ Walker 1989, 23-25; Symonds 2015, 87, Fig. 6.2.

${ }^{13}$ Symonds 2009, 955-956.
} 
Bogdan-Cătăniciu 1974

Gudea 1997

Gudea, Pop 1971

Gudea, Pop 1973

Gudea, Pop 1974-1975

Gudea, Pop 1975

Fleer 2004

IDR III/4

Macrea 1944

Macrea 1969

Marcu 2009

Petculescu et alii 2013

Petculescu et alii 2014

Petculescu et alii 2015

Petculescu et alii 2016

Petculescu et alii 2017

Petculescu et alii 2018

Piso 1993

Symonds 2009

Symonds 2015

Țentea, Matei-Popescu 2015

Vlădescu 1983

Walker 1989

\section{BIBLIOGRAFIE}

I. Bogdan Cătăniciu 1974 - I. Bogdan Cătăniciu, Cercetări în castellum de la Rucăr, SCIVA, 25, 2, p. 277-288

N. Gudea, Der dakische Limes. Materialien zu seiner Geschichte, Jahrbuch des Römisch-Germanischen Zentralmuseum, Mainz, 44, p. 1-113

N. Gudea, I. Pop, Castrul roman de la Râşnov-Cumidava. Contribuții la cercetarea limesului de sud-est al Daciei romane, Braşov, 1971; varianta germană: Das Römerlager von Râşnov (Rosenau). Cumidava. Beiträge zu den Limesuntersuchungen im Südosten des römischen Dazien, Braşov, 1971

N. Gudea, I. Pop, Castrul roman de la Râşnov. Săpăturile din anul 1971, Cumidava, 7, 1973, p. 13-24

N. Gudea, I. Pop, Cercetări arheologice în castrul roman de la Râşnov, Studii şi Materiale de Muzeografie şi Istorie Militara, 7-8, 1974-1975, p. 55-78

N. Gudea, I. Pop, Castrul roman de la Râşnov. Săpăturile arheologice din anii 1973-1974. Raport preliminar, Cumidava, 8, 1974-1975, p. 56-72

Ch. Fleer, Typisierung und Funktion der Kleinbauten am Limes, în E. Schallmayer (Hrsg.), Limes Imperii Romani. Beiträge zum Fachkolloquium „Weltkulturerbe Limes“ November 2001 in Lich-Arnsburg (= SaalburgSchriften. 6), Bad Homburg v. d. H., 2004, p. 75-92

I.I. Russu, Inscripțiile Daciei romane, 4. Zona răsăriteană, București, 1988

M. Macrea, Cumidava, Anuarul Institutului de Studii Clasice, 4, 1941-1943 (1944), p. 234-261

M. Macrea, Viaţa în Dacia romană, București, 1969

F. Marcu, Organizarea internă a castrelor romane, Cluj-Napoca, 2009

L. Petculescu, S. Coşuleţ, R. Ştefănescu, I. Bauman, C. Mitar, D. Poltorak, Râşnov, jud. Braşov [Cumidava] Punct: Grădişte, Erdenburg, CCA, 2013, p. 175

L. Petculescu, S. Coşuleţ, R. Ştefănescu, I. Bauman, C. Mitar, D. Poltorak, Râşnov, jud. Braşov [Cumidava] Punct: Grădişte, Erdenburg, CCA, 2014, p. 113-114

L. Petculescu, S. Coşuleţ, C. Mitar, D. Poltorak, Râşnov, jud. Braşov [Cumidava] Punct: Grădişte, Erdenburg, CCA, 2015, p. 62-63

L. Petculescu, S. Coşuleţ, C. Mitar, A. Gonciar, D. Poltorak, T. Dumbrăveanu, Râşnov, jud. Braşov [Cumidava] Punct: Grădişte, Erdenburg, CCA, 2016, p. 68-69

L. Petculescu, S. Coşuleţ, C. Mitar, J. Miller, I. Dumitrescu, T. Dumbrăveanu, Râşnov, jud. Braşov [Cumidava] Punct: Grădişte, Erdenburg, CCA, 2017, p. 111-112

L. Petculescu, S. Coșuleț, C. Mitar, T. Dumbrăveanu, Râșnov, jud. Brașov [Cumidava]. Punct: Grădiște, Erdenburg, CCA, 2018 (în curs de apariție).

I. Piso, Fasti provinciae Daciae I. Die senatorischen Amtsträger, Bonn, 1993

M.F.A. Symonds, Fortlets and their adaptation for artificial frontiers, în A. Morillo, N. Hanel, E. Martín, Madrid Á. Morrillo (eds), Limes XX: Estudios sobre la Frontera Romana. Roman Frontier Studies, vol. II, Anejo de Gladius 13, León, Spain, September 2006, p. 955-963

M.F.A. Symonds, The curious incidence of fortlets in the Pennines, in D.J. Breeze, R.H. Jones, and I.A. Oltean (eds), Understanding Roman frontiers: papers offered to Professor Bill Hanson on the occasion of his retirement John Donald, Edinburgh, p. 82-100

O. T,entea, Fl. Matei-Popescu, Why there? The preliminaries of constructing the Roman Frontier in South-East Dacia, $A M N$, 2015, p. 109-130

C. M. Vlădescu, Armata romană în Dacia Inferior, București, 1983

L. Walker, Castleshaw: The Archaeology of a Roman Fortlet, Greater Manchester Archaeological Unit, 1989, p. 23-25 


\section{LIST OF ILLUSTRATIONS}

FigURE 1: I. Map of the Roman Frontiers in Romania, with the localization of Râșnov roman fort (LIMES National Program - https://limesromania.ro/ro/articole/despre-proiect)

FIGURE 2: The fort and civil settlement from Râșnov, detail from orthophotoplan (Daniel Costea - 2016 (CMNIR)

FIGURE 3. The plan of the Râşnov Fort, after archaeological research (after Marcu 2009, 298, pl. 30)

FIGURE 4: The correlation between the published archaeological research from Râşnov and the geophysics surveys from 2016.

OVIDIU ȚENTEA

Muzeul Naţional de Istorie a României ovidiu.tentea@gmail.com

ALEXANDRU POPA

Muzeul Național al Carpaților Răsăriteni alex.popa@live.de LIVIU PETCULESCU

Muzeul Național de Istorie a României liviu pliviu2011@gmail.com 